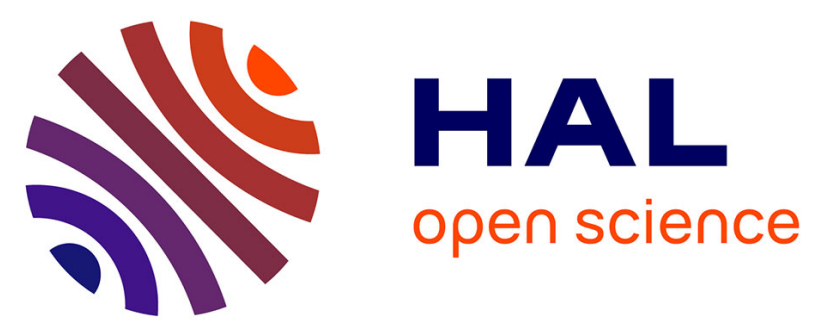

\title{
Insights into the Crystal Structure and Clathration Selectivity of Organic Clathrates Formed with Hydroquinone and (CO2 + CH4) Gas Mixtures
}

\author{
Jean-Philippe Torre, Heinz Gornitzka, Romuald Coupan, Christophe
}

Dicharry, Martín Pérez-Rodríguez, Antonio Comesaña, Manuel M. Piñeiro

\section{To cite this version:}

Jean-Philippe Torre, Heinz Gornitzka, Romuald Coupan, Christophe Dicharry, Martín PérezRodríguez, et al.. Insights into the Crystal Structure and Clathration Selectivity of Organic Clathrates Formed with Hydroquinone and (CO2 + CH4) Gas Mixtures. Journal of Physical Chemistry C, 2019, 123 (23), pp.14582-14590. 10.1021/acs.jpcc.9b04081 . hal-02279913

\section{HAL Id: hal-02279913 https://hal.science/hal-02279913}

Submitted on 5 Sep 2019

HAL is a multi-disciplinary open access archive for the deposit and dissemination of scientific research documents, whether they are published or not. The documents may come from teaching and research institutions in France or abroad, or from public or private research centers.
L'archive ouverte pluridisciplinaire HAL, est destinée au dépôt et à la diffusion de documents scientifiques de niveau recherche, publiés ou non, émanant des établissements d'enseignement et de recherche français ou étrangers, des laboratoires publics ou privés. 


\section{OATAO \\ Open Archive Toulouse Archive Ouverte}

\section{Open Archive Toulouse Archive Ouverte}

OATAO is an open access repository that collects the work of Toulouse researchers and makes it freely available over the web where possible

This is an author's version published in: http://oatao.univ-toulouse.fr/24197

Official URL: https://doi.org/10.1021/acs.jpcc.9b04081

\section{To cite this version:}

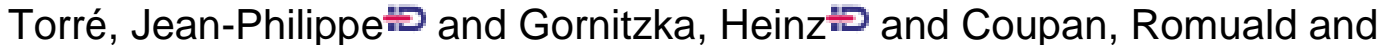
Dicharry, Christophe and Pérez-Rodríguez, Martín and Comesaña, Antonio and Piñeiro, Manuel M. Insights into the Crystal Structure and Clathration Selectivity of Organic Clathrates Formed with Hydroquinone and (CO2+ CH4) Gas Mixtures. (2019) The Journal of Physical Chemistry C, 123 (23). 14582-14590. ISSN 1932-7447

Any correspondence concerning this service should be sent to the repository administrator: tech-oatao@listes-diff.inp-toulouse.fr 


\title{
Insights into the Crystal Structure and Clathration Selectivity of Organic Clathrates Formed with Hydroquinone and $\left(\mathrm{CO}_{2}+\mathrm{CH}_{4}\right) \mathrm{Gas}$ Mixtures
}

\author{
Jean-Philippe Torré, ${ }^{* \dagger \odot}$ Heinz Gornitzka, ${ }^{\ddagger}$ Romuald Coupan, ${ }^{\S}$ Christophe Dicharry, \\ Martín Pérez-Rodríguez, ${ }^{\perp}$ Antonio Comesaña, ${ }^{\perp}$ and Manuel M. Piñeiro ${ }^{\perp}$ (1) \\ †Laboratoire de Génie Chimique, Université de Toulouse, CNRS, INPT, UPS, 31000 Toulouse, France \\ ${ }^{\ddagger}$ Laboratoire de Chimie de Coordination LCC-CNRS, Université de Toulouse, CNRS, UPS, 31400 Toulouse, France \\ ${ }^{\S}$ Total Research \& Technology Feluy, Zone Industrielle Feluy C, B-7181 Seneffe, Belgium \\ "CNRS/TOTAL/UNIV PAU \& PAYS ADOUR/E2S UPPA, Laboratoire des Fluides Complexes et leurs Réservoirs-IPRA, \\ UMR5150-avenue de l'Université, 64000 Pau, France \\ ${ }^{\perp}$ Departamento de Física Aplicada, Facultade de Ciencias, Universidade de Vigo, 36310 Vigo, Spain
}

\begin{abstract}
Organic clathrates, particularly those formed by hydroquinone (HQ) and gas mixtures, have been far less studied than other inclusion compounds, such as gas hydrates. In this study, experiments and molecular dynamics simulations were performed on mixed $\left(\mathrm{CO}_{2}+\mathrm{CH}_{4}\right)-\mathrm{HQ}$ clathrates. Single crystals were synthesized using gas mixtures with different compositions, ranging from pure $\mathrm{CO}_{2}$ to pure $\mathrm{CH}_{4}$. The crystal structure, the guest occupancy in the clathrates, and the variation of the crystal lattice parameters according to clathrate composition were obtained by X-ray diffraction measurements. In addition, molecular dynamics simulations were performed on the same systems, with state-of-the-art molecular models and force fields. The experimental results obtained and the molecular dynamics simulation estimations were in good agreement. The clathration selectivity was also calculated on the basis of experimental results, and the composition of the solid phase was correlated with the composition of the gas phase at equilibrium. These new insights into these structures will be useful from both a fundamental and a practical point of view, particularly for further developing innovative gas separation techniques using HQ clathrates.
\end{abstract}

\section{INTRODUCTION}

The term "clathrate" refers to a solid-state supramolecular entity composed of a network of self-associating molecules (called hosts) forming cavities or channels in which other species (called guests) can be encaged. ${ }^{1}$ These host-guest complexes crystallize if the size of the cavities is compatible with the size and shape of the guests, but only under specific thermodynamic (i.e., temperature and pressure) conditions, and they are generally unstable if the cavities do not contain a certain fraction of guest molecules. Clathrate hydrates (usually known as gas hydrates or simply hydrates) represent the most studied category of clathrate compounds, ${ }^{2}$ particularly natural gas hydrates that have been known for their propensity to plug the flowlines used in oil and gas transportation. ${ }^{3}$ Clathrates whose framework is entirely made up of organic molecules are called organic clathrates. These compounds, particularly those formed with hydroquinone (HQ), have been far less studied than the well-known gas hydrates.

Hydroquinone (1,4 dihydroxybenzene, formerly referred to as quinol) is able to form organic clathrates by encaging gaseous guest molecules such as methane $\left(\mathrm{CH}_{4}\right)$, carbon dioxide $\left(\mathrm{CO}_{2}\right)$, sulfur dioxide $\left(\mathrm{SO}_{2}\right)$, hydrogen sulfide $\left(\mathrm{H}_{2} \mathrm{~S}\right)$ among others. ${ }^{4}$ The general formula of HQ clathrates is $\chi \mathrm{G}$ $3 \mathrm{C}_{6} \mathrm{H}_{4}(\mathrm{OH})_{2}$, where $\mathrm{G}$ stands for the encaged guest species and $\chi$ is the occupancy factor (i.e., the fraction of cavities that are occupied). Note that the value of $\chi$ might theoretically vary from 0 for a guest-free clathrate (if all of the cavities are empty) to 1 (if all of the cavities are fully occupied).

HQ clathrates (denoted by $\beta$-HQ), discovered more than 150 years ago ${ }^{5}$ and considered for ages as just a fascinating scientific oddity, actually have very interesting properties: (i) these crystals can store large quantities of gases; ${ }^{6}$ (ii) can release (or absorb) energy when the guests enter (or exit) the clathrate structure; ${ }^{7}$ in the case of some systems, (iii) have a very high stability at ambient conditions that is ideal for applying analytical characterization techniques; ${ }^{8}$ and (iv) can exist in a metastable state with no guests present in the lattice structure. $^{9,10}$ As a result, practical applications based on HQ clathrates have been proposed, including sequestration of hazardous substances, ${ }^{11}$ fractionation of organic compound 
mixtures, ${ }^{12}$ hydrogen storage, ${ }^{13,14}$ and separation of $\mathrm{CO}_{2}$ from different gas mixtures containing $\mathrm{H}_{2},{ }^{15} \mathrm{~N}_{2}{ }^{16}$ and $\mathrm{CH}_{4} \cdot{ }^{1717}$

In the late 1940s, Powell was the first ever to resolve an organic clathrate structure $\left(\mathrm{HQ}-\mathrm{SO}_{2}\right)$ by X-ray crystallographic analysis, revealing one of the key elements for understanding the nature of these compounds. ${ }^{18}$ However, more than 75 years on, it is amazing to realize just how many simple and basic organic clathrate systems still remain unexplored, particularly among those formed with gases. ${ }^{19,20}$ For example, the detailed molecular structures of $\mathrm{HQ}-\mathrm{CH}_{4}$ and mixed $\left(\mathrm{CH}_{4}-\mathrm{CO}_{2}\right)-\mathrm{HQ}$ clathrates have still not been published. Indeed, this area has not yet been thoroughly studied and HQ clathrates could open up interesting new scientific avenues for exploration.

When different guests are encaged in an HQ structure (typically when a gas mixture is used instead of a pure gas), the resulting host-guest compounds are known as "mixed gas HQ clathrates". ${ }^{21}$ Mixed gas clathrates could be used in a number of practical applications such as gas separation by selective clathration. However, there is very little fundamental information on mixed gas HQ clathrates in the literature, except for recent physicochemical characterizations, and in spectroscopic and thermodynamic data. ${ }^{9,22-24}$ From a crystallographic point of view, even less information is available. Lee et al. studied the properties of $\left(\mathrm{C}_{2} \mathrm{H}_{4}-\mathrm{CH}_{4}\right)-$ HQ and $\left(\mathrm{C}_{2} \mathrm{H}_{4}-\mathrm{C}_{2} \mathrm{H}_{6}\right)-\mathrm{HQ}$ clathrates and found that the lattice parameters $a, b$, and $c$ (calculated from X-ray powder diffraction patterns) generally increase with the concentration of $\mathrm{C}_{2} \mathrm{H}_{4}$ in the gas phase. ${ }^{25,26}$ However, to the best of the author's knowledge, no detailed crystal structures of the kind organic clathrates form with gas mixtures have ever been reported.

Molecular dynamics (MD) simulations of clathrates have been described in the literature, although there are not as many of them as one might expect, considering the abundance and availability of certain host molecules such as water or HQ. Among the clathrates, gas hydrates are by far the systems that receive the most attention in simulation studies. Several reviews, those of Sum et al. ${ }^{27}$ and Barnes and Sum, ${ }^{28}$ for example, offer detailed theoretical descriptions of their thermophysical properties and equilibrium phenomena simulated by MD. HQ clathrates have received far less attention in molecular dynamics studies, although they share many structural features with hydrate clathrates. To our knowledge, the first study was presented by Dang and Pettitt, ${ }^{29}$ in which they investigated the thermodynamics and guest dynamics of krypton ( $\mathrm{Kr}$ ) and argon (Ar) HQ clathrates. ${ }^{30}$ This study was promptly followed by a second one by the same authors on diatomic molecules. Santikary et al. ${ }^{31}$ studied the diffusion of noble gases (neon and argon) through rigid HQ lattices. Daschbach et al. ${ }^{32}$ and more recently Pérez-Rodríguez et al. ${ }^{33}$ investigated the behavior of $\mathrm{H}_{2}$ as a guest molecule, whereas Nemkevich et al. ${ }^{34}$ studied HQ clathrates with Dianin's compound. Other guests including $\mathrm{CO}_{2}, \mathrm{CO}, \mathrm{H}_{2} \mathrm{~S}$, and $\mathrm{CH}_{4}$ were also previously modeled by Zubkus et al. ${ }^{35,36}$ Recently, a study of $\mathrm{HQ}$ clathrates with $\mathrm{CH}_{4}$ and $\mathrm{CO}_{2}$ as guest molecules was presented, ${ }^{37}$ in which only the clathrates of the two guests in their pure state (not their mixtures) were investigated. In this study, a molecular dynamics model based in an optimized potentials for liquid simulations (OPLS) force field was tested and the solid native $\alpha$ phase and the $\beta$ clathrate phases of HQ with $\mathrm{CH}_{4}$ and $\mathrm{CO}_{2}$ as guest molecules were reproduced with reasonable accuracy.
In the present study, we investigated the crystal structure of mixed $\left(\mathrm{CO}_{2}+\mathrm{CH}_{4}\right)-\mathrm{HQ}$ clathrates in a combined experimental and numerical approach. Single crystals were synthesized using $\mathrm{CO}_{2} / \mathrm{CH}_{4}$ gas mixtures with different compositions ranging from pure $\mathrm{CO}_{2}$ to pure $\mathrm{CH}_{4}$, and the crystal structure was resolved using X-ray diffraction (XRD). The main objective was to study how the lattice parameters of these mixed gas clathrates vary according to the proportion of $\mathrm{CO}_{2}$ and $\mathrm{CH}_{4}$ loaded in the crystal. The selectivity of the clathration (i.e., the capacity of the crystal to selectively encapsulate one of the two molecules present in the gas mixture used to form it) was also analyzed experimentally across the entire gas composition domain. In parallel, molecular dynamics simulations were performed on the same systems using state-of-the-art molecular models and force fields, namely, solving Newton's equations of motion for the individual atoms, coupled with a barostat and a thermostat to fix their thermodynamic conditions at the thermodynamic points of interest. Finally, the experimental and numerical results obtained were compared and discussed to offer salient conclusions regarding the structure and composition of these mixed gas organic clathrates.

\section{EXPERIMENTAL SECTION}

The gas clathrates are crystallized in a $168.0 \pm 0.9 \mathrm{~cm}^{3}$ highpressure jacketed reactor equipped with two viewing windows to watch the crystals growing during the experiment, two Pt100 probes to measure the liquid and gas temperatures with an accuracy of $\pm 0.1 \mathrm{~K}$, and a Keller pressure sensor (accuracy of $\pm 0.01 \mathrm{MPa}$ ). The protocol used here was previously used in another of the authors' studies to obtain $\mathrm{CO}_{2}-\mathrm{HQ}$ clathrate single crystals. ${ }^{8}$ In short, an oversaturated solution of HQ in absolute ethanol $(\mathrm{EtOH}),{ }^{38}$ typically $8 \mathrm{~g}$ of $\mathrm{HQ}$ in $11 \mathrm{~g}$ of $\mathrm{EtOH}$, is first prepared in a small glass vessel containing a starshaped magnetic stirring bar. This vessel is placed inside the reactor in front of the viewing windows with the help of a clamp. The reactor is then closed, put under vacuum to eliminate any traces of air, and regulated to a temperature of $298 \pm 0.1 \mathrm{~K}$. The initial HQ/EtOH suspension is agitated with a magnetic stirrer situated beneath the reactor to properly dissolve the HQ and saturate the solvent. The agitation is stopped to perform the next operations in quiescent conditions. The reactor is pressurized either with pure $\mathrm{CO}_{2}$ (or $\mathrm{CH}_{4}$ ) or with a $\mathrm{CO}_{2}-\mathrm{CH}_{4}$ gas mixture until the desired pressure of $3.0 \mathrm{MPa}$ is reached. The temperature and pressure used in this work were chosen based on previous studies by the authors, particularly two: the first is a process evaluation of $\mathrm{CO}_{2} / \mathrm{CH}_{4}$ separation by $\mathrm{HQ}$ clathrate formation in which a temperature of $298 \mathrm{~K}$ and a pressure of $3.0 \mathrm{MPa}$ could be a relevant operating point for an industrial production gas separation unit using such a technology; ${ }^{17}$ the second presents a wide range of physical and chemical characterization results for $\left(\mathrm{CO}_{2}-\mathrm{CH}_{4}\right)-\mathrm{HQ}$ clathrates obtained at ambient conditions and $3.0 \mathrm{MPa}$ but did not study crystal structures. ${ }^{24}$ Both temperature and pressure are maintained constant during crystallization. The crystals inside the reactor are observed using a commercial webcam (LiveCam Optia AF, Creative Labs), and all of the process data (i.e., pressure and temperature versus time) are recorded using a homemade LabVIEW interface with an acquisition frequency of $1 \mathrm{~Hz}$. At the end of the synthesis, the composition of the gas mixture at equilibrium with the clathrates is analyzed by gas chromatography (GC). The reactor is then isolated (i.e., the gas supply 
valve is closed) and transported (under pressure) to the analytical room for XRD analysis. It is depressurized and opened to collect the clathrate crystals, and the XRD analysis is performed immediately at $100 \mathrm{~K}$. Technical details on GC, XRD apparatus and methods, and information about the equipment used in this work are summarized in Tables S1 and S2 of the Supporting Information. Figures showing the crystal structure and the voids were obtained using Mercury 3.10.3. ${ }^{39}$

\section{NUMERICAL METHODS}

For simulating the mixed gas HQ clathrate, we use a molecular dynamics technique based on molecular models and a methodology previously tested for pure $\mathrm{CO}_{2}$ and $\mathrm{CH}_{4} \mathrm{HQ}$ clathrates. ${ }^{37}$ GROMACS software ${ }^{40,41}$ is used to carry out all $\mathrm{MD}$ simulations in the present work.

The initial coordinates of the HQ lattice are obtained from experimental crystallographic data acquired by X-ray diffraction analysis. ${ }^{8}$ The simulation boxes for the $\beta$-HQ clathrates are shown in Figure 1. The initial cell parameters of $\beta$-HQ are taken from the experimental values $a=b=1620.7 \pm 0.6 \mathrm{pm}$,

(a)
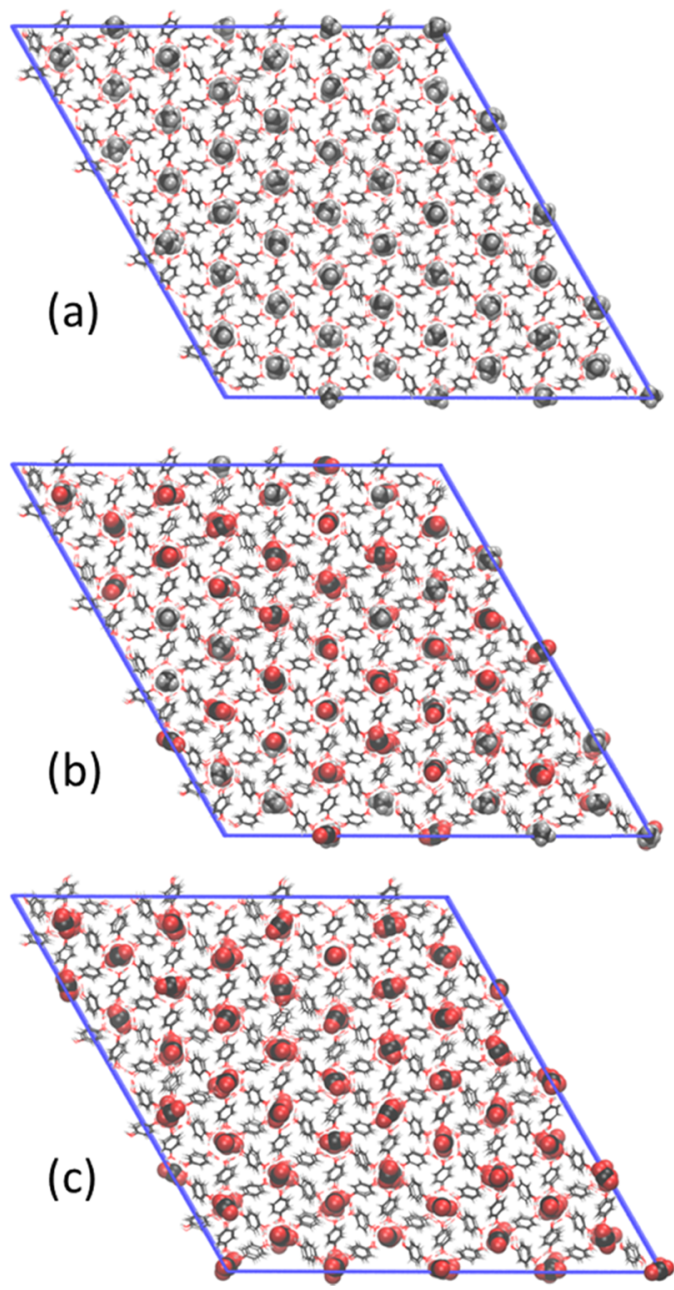

Figure 1. Snapshot of the rhombohedral simulation boxes for the $\beta$ HQ clathrate, containing as guest molecules (a) $\mathrm{CH}_{4}$, (b) an equimolar concentration of $\mathrm{CO}_{2}$ and $\mathrm{CH}_{4}$, and (c) $\mathrm{CO}_{2}$. The views were taken along the $z$-axis, so the clathrate channels are perpendicular to the page plane. Each channel, consisting, for this system size, four aligned cells, shows the superimposition of all of the guest molecules it contains. $c=578.0 \pm 0.2 \mathrm{pm}$. We fill the $\beta$-HQ lattice with different concentrations of $\mathrm{CO}_{2}$ and $\mathrm{CH}_{4}$, and each system is then equilibrated at the desired temperature and pressure values. We select the OPLS-all atom (AA) ${ }^{42}$ force field, somewhat modified for modeling the HQ lattice and guest molecules. In the model used here, the $\mathrm{C} 6$ rings in the HQ molecules are rigid, as are the $\mathrm{CO}_{2}$ and $\mathrm{CH}_{4}$ guest molecules, but the $\mathrm{OH}$ moieties have some freedom to rotate. All of the molecules are supposed to be nonpolarizable, meaning that the atoms are modeled as point particles with fixed relative positions and point charges.

The modifications made to the OPLS-AA force field used in this study concern the atomic equilibrium positions and charges recalculated from quantum mechanics (QM) instead of the default values in the force field tables. To ensure compatibility with the original OPLS-AA parameterization scheme, equilibrium geometries of $\mathrm{HQ} \mathrm{CO}_{2}$, and $\mathrm{CH}_{4}$ are obtained using Becke's three-parameter hybrid functional B3LYP (Becke, Lee-Yang-Parr) ${ }^{43,44}$ with the $6-31+G(d, p)$ Pople basis set implemented in Gaussian 09. ${ }^{45}$ Atomic point charges are recalculated with the help of the CHELPG scheme developed by Breneman and Wiberg ${ }^{46}$ in Gaussian 09 too.

The initial simulation boxes are prepared (optimized and equilibrated) in the canonical (NVT) ensemble, coupled with the thermostat by Bussi et al. ${ }^{47}$ When the simulation boxes are stabilized, we calculate the lattice parameters of the mixed gas HQ clathrate crystal structures by performing independent simulations with different relative concentrations of guest molecules in the isothermal-isobaric ( $\mathrm{NpT}$ ) ensemble. The pressure is stabilized at selected values by means of the Parrinello-Rahman barostat ${ }^{47}$ using anisotropic compressibility to take into account the rhombohedral symmetry of the HQ clathrate crystal. As usual, three-dimensional (3D) periodic boundary conditions are used in conjunction with the minimum image convention. The interaction potentials are truncated so that the explicit interactions remain inside the simulation box. Cutoff values of $110 \mathrm{pm}$ are used for both the Lennard-Jones and Coulombic potentials. To evaluate these interactions, we chose the fourth-order particle mesh Ewald method $^{48,49}$ with a ratio mesh of $120 \mathrm{pm}$. To describe cross interactions, we use the Lorentz-Berthelot combining rules with a geometric mean. ${ }^{50}$

\section{RESULTS AND DISCUSSION}

A summary of the experimental results obtained in this study is given in Table S3 of the Supporting Information, including $\mathrm{CO}_{2}$ molar fraction in the gas phase in equilibrium with the solid phase measured at the end of the experiment, $A$ and $B$ parameters of the clathrate formula, crystal lattice parameters $(a, b, c)$, tilt angle of the HQ molecule in the crystal $(\alpha)$, volume of the unit cell $\left(V_{\mathrm{uc}}\right)$, total occupancy of the guests in the clathrate $(\chi), \mathrm{CO}_{2}$ molar fraction in the crystal $\left(x^{\mathrm{CO}_{2}}\right)$, ratio of the $\mathrm{CO}_{2}$ and $\mathrm{CH}_{4}$ molar fractions in the crystal $\left(S^{\mathrm{CO}_{2} / \mathrm{CH}_{4}}\right)$, and separation factor $\left(\mathrm{SF}^{\mathrm{CO}_{2} / \mathrm{CH}_{4}}\right)$.

Crystal Structure. The modeled crystal structure is shown in Figure 2. Figure $3 a-c$ shows general views of the host crystal structure for the mixed $\left(\mathrm{CO}_{2}+\mathrm{CH}_{4}\right)-\mathrm{HQ}$ clathrates obtained experimentally. The global rhombohedral structure (symmetry group $R \overline{3}$ ) is the same whether the clathrates are obtained with mixed or pure gases (i.e., $\mathrm{CO}_{2}$ and $\mathrm{CH}_{4}$ ). The geometry is based on the formation of two interpenetrating, but not interconnected, networks of HQ molecules forming a cavity in which the guest molecules are encapsulated. The hydroxyl 


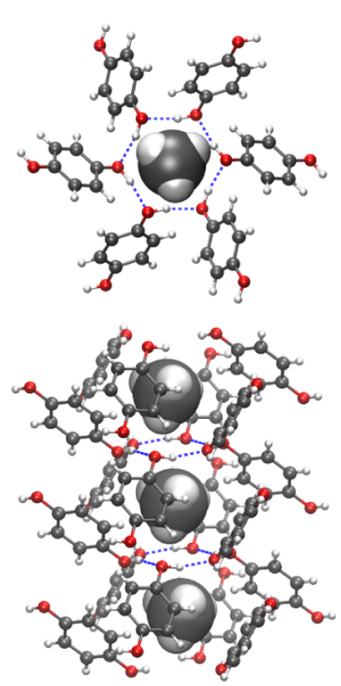

(a)

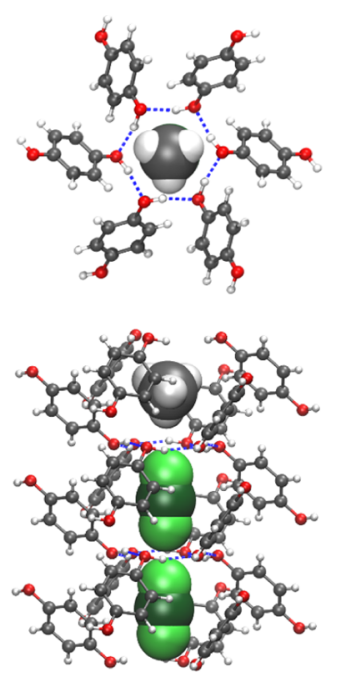

(b)
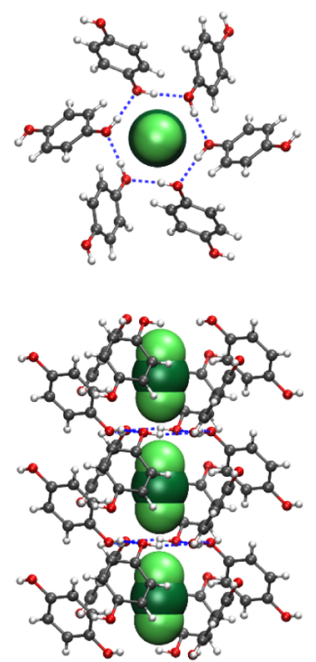

(c)

Figure 2. Detailed view of the molecular dynamics simulation structure for the $\beta$-HQ clathrates, showing only three consecutive cells of a given channel. (a) Channel containing $\mathrm{CH}_{4}$ as a guest molecule, (b) channel containing $\mathrm{CO}_{2}+\mathrm{CH}_{4}$, and (c) channel containing $\mathrm{CO}_{2}$. In each case, a vertical (along the $z$-axis) and a side (along the $x$-axis) view are presented.
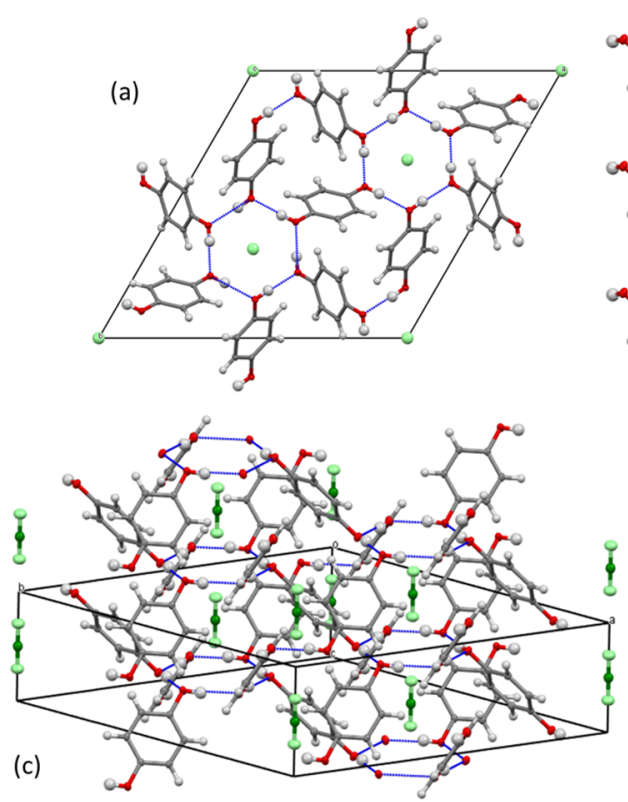

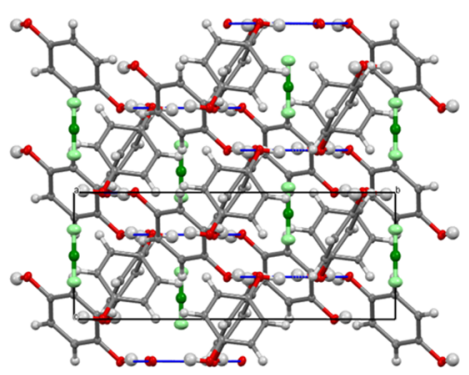

(b)

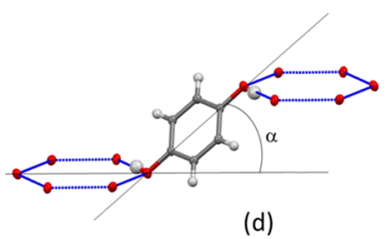

(d)

Figure 3. General views of the crystal structure of mixed $\left(\mathrm{CO}_{2}-\mathrm{CH}_{4}\right)-\mathrm{HQ}$ clathrates obtained experimentally: (a) view down the crystallographic $c$-axis; (b) view down the crystallographic $a$-axis; and (c) 3D view. Blue dotted lines are hydrogen bonds forming the planar hexagons at the top and bottom of the cavity. (d) HQ molecule is represented with its oxygen-oxygen axis tilted at an angle $\alpha$ to the $c$ plane (0001). The structures presented in this figure were built with the clathrate $\left(0.59 \mathrm{CO}_{2}-0.23 \mathrm{CH}_{4}\right)-3 \mathrm{HQ}(\mathrm{CDCC}-1913200)$.

groups of HQ are linked by hydrogen bonding and form a planar hexagon defining the top and bottom of this cavity, whereas alternate HQ molecules pointing diagonally above and below each hexagon define the lateral parts of the cavity. Interestingly enough, we found that all of the clathrates analyzed in this study have the same crystallographic structure. The lattice parameters, however, strongly depend on the composition of the gas loaded into the clathrates, as discussed later on. In addition to the lattice parameters, the $\alpha$ angle (tilt angle of the $\mathrm{O}-\mathrm{O}$ HQ molecule axis in relation to the $c$ plane) shown in Figure $3 \mathrm{~d}$ also characterizes the structure. In an attempt to get a better idea of the cavity shape, Figure 4 shows the voids present in the crystal, focusing on the solvent- accessible surface areas. With this approximation, the crystal is considered as a set of fused spheres with van der Waals radii. A probe sphere (of a defined radius) is then rolled over the van der Waals surface, and the accessible surface is mapped out by the center of the probe sphere to obtain a $3 \mathrm{D}$ view of the voids in the crystal. ${ }^{51}$ This method has already been used to characterize various materials such as salycilamide polymorphs, ${ }^{52}$ L-alanyl-L-valine, ${ }^{53}$ gabapentin heptahydrate, ${ }^{54}$ and adamantane hydrochloride salts. ${ }^{55}$ The HQ clathrate cavity exhibits a roughly spherical shape with pure $\mathrm{CH}_{4}$ (see Figure $4 a)$, whereas it is largely elongated toward the $c$-axis in the case of pure $\mathrm{CO}_{2}$ (see Figure 4b). Interestingly enough, the cavity shape of the mixed $\left(\mathrm{CO}_{2}-\mathrm{CH}_{4}\right)-\mathrm{HQ}$ clathrates is halfway 


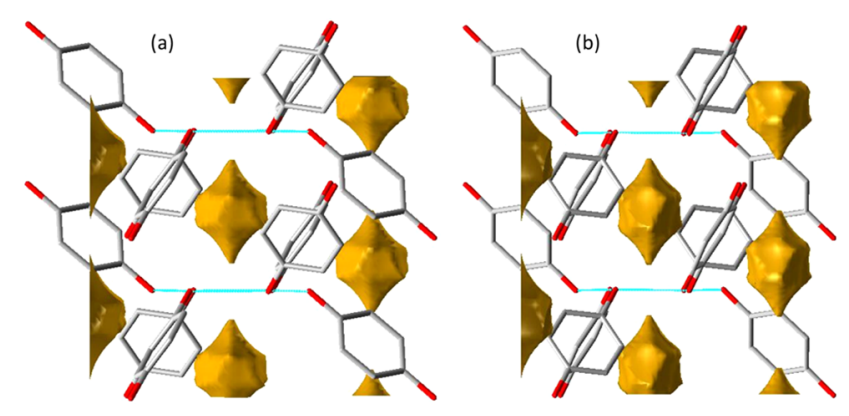

Figure 4. Representations of typical cavities in HQ clathrates (down the crystallographic $a$-axis) obtained from a crystal structure analysis by XRD. The "solvent-accessible voids" are visualized using a probe sphere of $1.2 \AA$ and a grid spacing of $0.2 \AA$. (a) $\mathrm{CH}_{4}-\mathrm{HQ}$ clathrate. (b) $\mathrm{CO}_{2}-\mathrm{HQ}$ clathrate.

between those obtained with pure gases: the more $\mathrm{CO}_{2}$ enclathrated in the cavity, the more deformed it is.

As both $\mathrm{CO}_{2}$ and $\mathrm{CH}_{4}$ are enclathrated, the formula of the mixed $\left(\mathrm{CO}_{2}+\mathrm{CH}_{4}\right)$ clathrate can be written as:

$\left(A \mathrm{CO}_{2}+B \mathrm{CH}_{4}\right) \cdot 3 \mathrm{HQ}$, with $A+B=\chi$ with $(0 \leq \chi \leq 1)$ and where $A$ and $B$ are defined as the $\mathrm{CO}_{2}$ and $\mathrm{CH}_{4}$ occupancy factors, respectively. These factors can be normalized by the global occupancy $\chi$ to give normalized occupancy factors $x^{\mathrm{CO}_{2}}$ $=A / \chi$ and $x^{\mathrm{CH}_{4}}=B / \chi$. The values $x^{\mathrm{CO}_{2}}$ and $x^{\mathrm{CH}_{4}}$ are the molar fractions of the $\mathrm{CO}_{2}$ and $\mathrm{CH}_{4}$ trapped inside the clathrate. The composition of the clathrate was calculated by structural analysis. For this purpose, the carbon and oxygen atom occupancies in the guest molecules were refined separately using two different variables. Given that the carbon atoms of both guest molecules are located in the same position, the variable for carbon atom occupancy gives the total occupancy of the guest molecules. The value of the oxygen atom variable reflects the $\mathrm{CO}_{2}$ occupancy and the difference between the two variables gives the information pertaining to the $\mathrm{CH}_{4}$ molecules. It has been proven that this technique gives occupancy values of the same order of magnitude as those obtained by TGA measurements. ${ }^{8}$ In this work, the occupancies and clathrate formulas determined by XRD analysis were crosschecked by elementary analysis. In addition, the reproducibility of the experiments, estimated based on three independent runs carried out in the same conditions using an initial 50:50 $\mathrm{CO}_{2} / \mathrm{CH}_{4}$ gas mixture, is quite good as the average results obtained by structural analysis were $A=$ $0.57 \pm 0.03$ and $B=0.22 \pm 0.03$ against $A=0.52 \pm 0.12$ and $B$ $=0.19 \pm 0.07$ by elementary analysis.

The experimental values of parameters $A$ and $B$ of the clathrate formula $\left(A \mathrm{CO}_{2}+B \mathrm{CH}_{4}\right) \cdot 3 \mathrm{HQ}$ are plotted in Figure 5 versus the molar fraction of $\mathrm{CO}_{2}$ in the gas phase in equilibrium with the crystal. It is therefore very simple using these curves to obtain the clathrate formula for a given gas composition at $298 \mathrm{~K}$ and $3 \mathrm{MPa}$. Interestingly enough, both the crystal lattice parameters, i.e., $a(=b)$ and $c$, obtained experimentally and by modeling appear to be directly correlated with the clathrate composition. The variation of the lattice parameters and the angle $\alpha$ versus $x^{\mathrm{CO}_{2}}$ are shown in Figures 6 and 7, respectively. Note that as $x^{\mathrm{CH}_{4}}=1-x^{\mathrm{CO}_{2}}$, the variation of the lattice parameters versus $x^{\mathrm{CH}_{4}}$ can be deduced very easily.

When the clathrate became increasingly rich in $\mathrm{CO}_{2}$, we observed both a decrease in the $a(=b)$ lattice parameter and an increase in the $c$ parameter: the size of the unit cell is

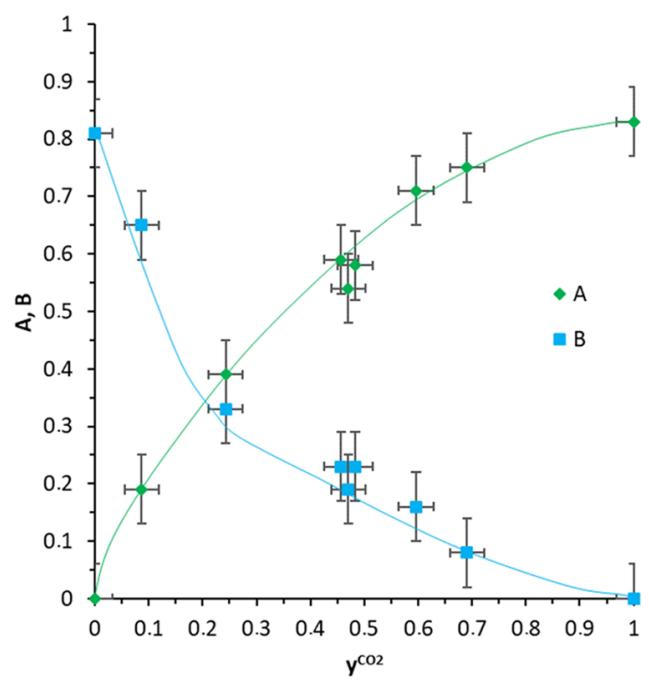

Figure 5. Variation of $A$ and $B$ (parameters of the clathrate formula $\left.\left(A \mathrm{CO}_{2}+B \mathrm{CH}_{4}\right) \cdot 3 \mathrm{HQ}\right)$ as a function of the molar fraction of $\mathrm{CO}_{2}$ in the gas phase at equilibrium with the crystal. Experimental data were obtained with clathrates synthesized at $T=298 \mathrm{~K}$ and $P=3.0 \mathrm{MPa}$ and analyzed with XRD at $T=100 \mathrm{~K}$ and $P=0.1 \mathrm{MPa}$. The blue and green lines are guides for the eye.

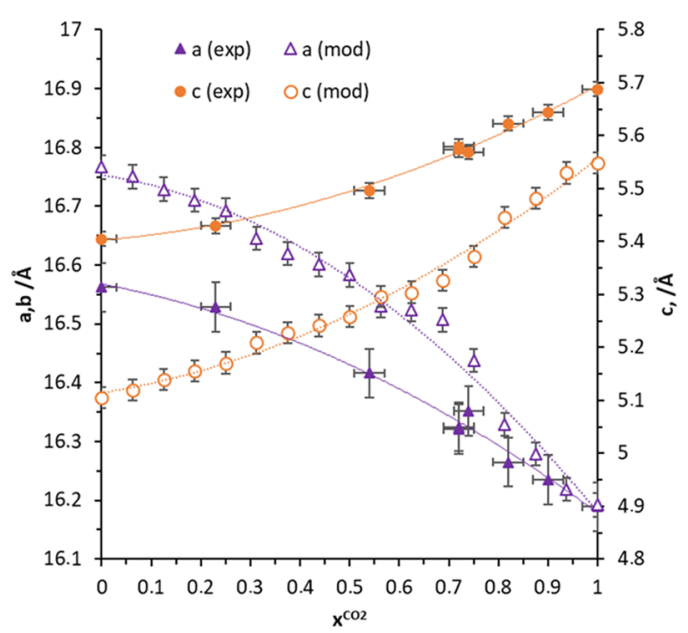

Figure 6. Variation of the lattice parameters of the $\left(\mathrm{CO}_{2}+\mathrm{CH}_{4}\right)-$ $\mathrm{HQ}$ clathrate crystals as a function of the molar fraction of $\mathrm{CO}_{2}$ in the solid phase. Experimental data were obtained with clathrates synthesized at $T=298 \mathrm{~K}$ and $P=3.0 \mathrm{MPa}$ and analyzed with $\mathrm{XRD}$ at $T=100 \mathrm{~K}$ and $P=0.1 \mathrm{MPa}$. Modeling data were obtained at $T=100 \mathrm{~K}$ and $P=0.1 \mathrm{MPa}$. The orange and purple lines are guides for the eye.

therefore strongly dependent on the composition of the gas encapsulated in the clathrate. With this particular binary gas mixture and in these conditions, the variation of the lattice parameters is monotonous (no extremum found). This trend clearly demonstrates that the HQ framework is highly adaptive.

We observed that $\mathrm{MD}$ estimates almost systematically deviate from experimental values, but, despite this, the performance of the HQ molecular model and the force field used can be considered quantitatively good. Let us recall that the HQ force field used combines two different approaches. First, the dispersive interaction parameters were originally computed in a group contribution scheme for substituted benzene derivatives in the OPLS force field. It is important to note that dispersive characteristic parameters are adjusted to 


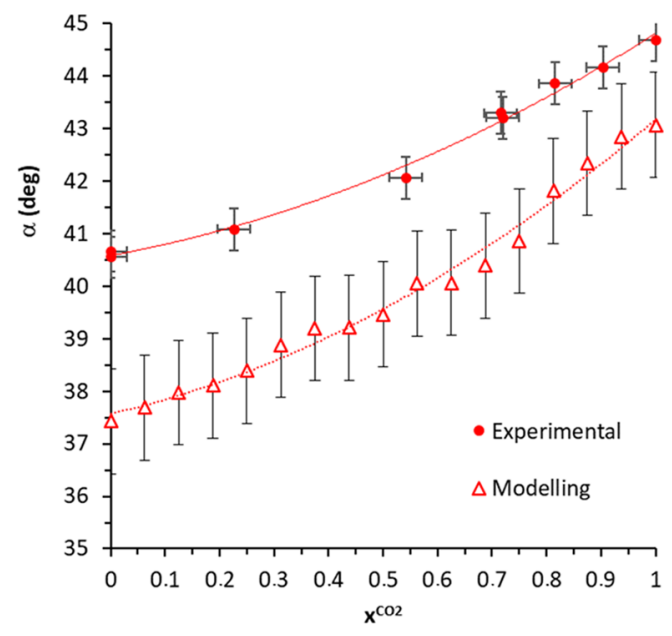

Figure 7. Variation of the $\alpha$ angle (tilt angle of the HQ molecule axis in relation to the $c$ plane) as a function of the molar fraction of $\mathrm{CO}_{2}$ in the solid phase. Experimental data were obtained with clathrates synthesized at $T=298 \mathrm{~K}$ and $P=3.0 \mathrm{MPa}$ and analyzed with XRD at $T=100 \mathrm{~K}$ and $P=0.1 \mathrm{MPa}$. Modeling data were obtained at $T=100$ $\mathrm{K}$ and $P=0.1 \mathrm{MPa}$. The red lines are guides for the eye.

reproduce experimental fluid-phase equilibrium data. The same applies for $\mathrm{CO}_{2}$ and $\mathrm{CH}_{4}$ force fields. The original $\mathrm{HQ}$ molecular model was then modified by recalculating the atomic point electric charges using QM calculations for an isolated molecule under vacuum. This means that the force field characteristic parameters were determined in conditions far removed from those studied for the present clathrates, underlining the remarkable transferability of force field parameters. The geometry of the HQ clathrate containing a single guest was found to be very similar to the results obtained in experiments, ${ }^{37}$ an encouraging first result. Because we are able to demonstrate that the clathrate structure is flexible enough to accommodate a mixed population of guest molecules, in keeping with the trend highlighted in experiments concerning the variation of $a$ and $c$ lattice parameters, these simulation results can be considered highly relevant in light of the hypotheses and simplifications used in the models (conventional, nonpolarizable, etc.). There was a certain drift in the estimated results, but the structural modification undergone by the clathrate with the change in guest composition is extremely subtle in experiments, and the simulations were able to very accurately capture this physical behavior.

Drawing on the analysis of the molecular dynamics simulation results, the shape of the clathrate cavities of the mixed clathrates can also be discussed. In the case of pure guest $\left(\mathrm{CH}_{4}\right.$ or $\left.\mathrm{CO}_{2}\right) \mathrm{HQ}$ clathrates, it is clear that all cavities have the same geometry, with a given set of lattice parameter values, regardless of the fluctuations in cage size due to the movement of the HQ molecules, which are bonded by labile hydrogen bonds only. Nevertheless, in the case of mixed guest clathrates, there is some controversy about the possible coexistence of clathrate cavities of different sizes for each type of guest molecule. Based on an analysis of the molecular dynamics simulation trajectory, a histogram of the $\alpha$ angle values for the pure $\mathrm{CH}_{4}$, pure $\mathrm{CO}_{2}$, and equimolar guest clathrate structures was calculated at $100 \mathrm{~K}$ and $0.1 \mathrm{MPa}$. The data obtained follow a normal distribution (see details of the statistical analysis in Table S4 of the Supporting Information).
The results presented in Figure 8 show a clearly monomodal cavity size distribution for the mixed clathrate too, which rules

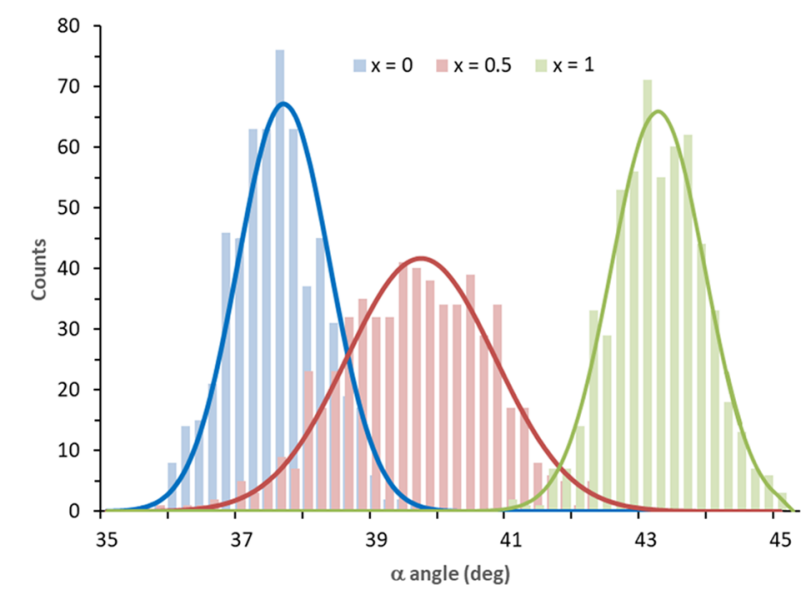

Figure 8. Distribution of the HQ molecule tilt angle $(\alpha)$ in the clathrate structure for three values of $\mathrm{CO}_{2}$ molar fractions in the solid phase $(x): x=0$ in blue $\left(\mathrm{CH}_{4}-3 \mathrm{HQ}\right) ; x=0.5$ in red $\left(0.5 \mathrm{CO}_{2}+\right.$ $\left.0.5 \mathrm{CH}_{4}\right)-3 \mathrm{HQ} ; x=1$ in green $\left(\mathrm{CO}_{2}-3 \mathrm{HQ}\right)$, each computed from 576 data points obtained by molecular dynamics simulations at $100 \mathrm{~K}$ and 0.1 MPa. Distribution histograms have been plotted with a class size of $0.2^{\circ}$. The solid curves correspond to the normal distribution calculated from the data points.

out the bimodal cage size distribution hypothesis. Molecular dynamics simulation results also support the case of a homogeneous crystalline structure with lattice parameters evolving continuously between the limiting values corresponding to the pure clathrates. This is an estimation result that might have been expected a priori, taking into consideration the reported flexibility of the hydrogen-bonded network of the clathrate structure, which is able to shrink or swell according to changes in guest occupancy rate or composition.

Clathrate Selectivity. The capacity of a clathrate crystal formed with a binary gas mixture to be more or less selective toward one of the two gases in presence can be discussed with the help of the separation factor (denoted SF), ${ }^{56}$ which considers both the composition of the enclathrated gas and the composition of the gas phase in equilibrium with the solid phase. This indicator, commonly used in chemical and process engineering studies to quantify clathrate selectivity toward one of the two gases, is expressed in eq 1 for the $\mathrm{CO}_{2} / \mathrm{CH}_{4}$ binary mixture as

$$
\mathrm{SF}^{\mathrm{CO}_{2} / \mathrm{CH}_{4}}=\frac{x^{\mathrm{CO}_{2}} /\left(1-x^{\mathrm{CO}_{2}}\right)}{y^{\mathrm{CO}_{2}} /\left(1-y^{\mathrm{CO}_{2}}\right)}
$$

where $x^{\mathrm{CO}_{2}}$ and $y^{\mathrm{CO}_{2}}$ are the $\mathrm{CO}_{2}$ molar compositions of the gas present in the clathrate and in the gas phase in the $\mathrm{CO}_{2} / \mathrm{CH}_{4}$ gas mixture, respectively. The higher the $\mathrm{SF}$, the better the selective clathration toward $\mathrm{CO}_{2}$.

The composition of the clathrate itself can be simply assessed by the $S^{\mathrm{CO}_{2} / \mathrm{CH}_{4}}$ ratio of the molar fraction of the two gases (i.e., $x^{\mathrm{CO}_{2}}$ and $x^{\mathrm{CH}_{4}}$ ) present in the crystal, defined by eq 2

$$
S^{\mathrm{CO}_{2} / \mathrm{CH}_{4}}=\frac{x^{\mathrm{CO}_{2}}}{x^{\mathrm{CH}_{4}}}
$$

In our case, it is worth noting that $S$ can also be directly calculated by the ratio of the $A$ and $B$ coefficients in the 
clathrate formula. Obviously, when $S^{\mathrm{CO}_{2} / \mathrm{CH}_{4}}>1$, the clathrate has more $\mathrm{CO}_{2}$ than $\mathrm{CH}_{4}$.

The correlation curve between the composition of the solid and the gas at equilibrium is shown in Figure 9 for a temperature of $298 \mathrm{~K}$. The corresponding values of $S$ and SF versus the $\mathrm{CO}_{2}$ concentration in the gas phase at equilibrium are plotted in Figure 10.

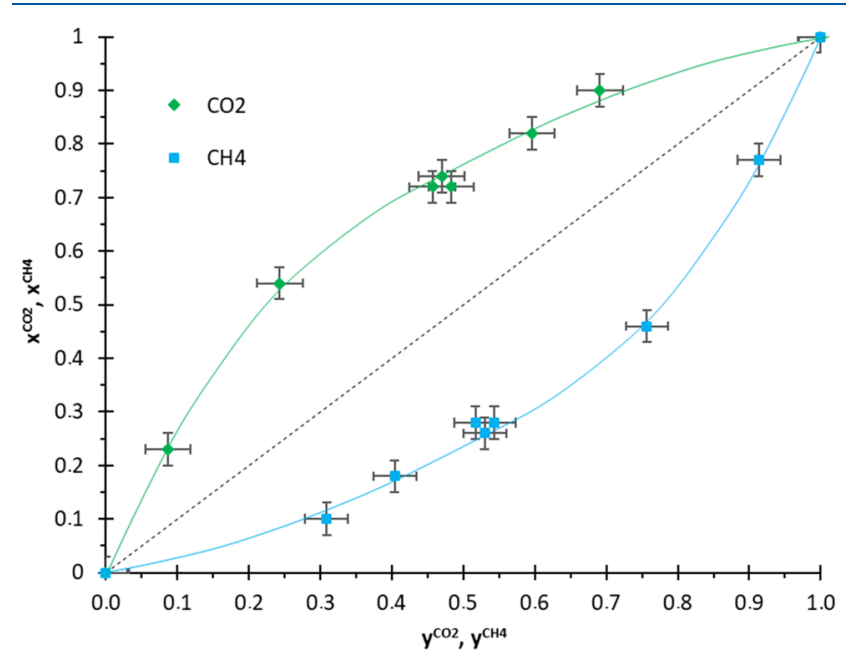

Figure 9. Equilibrium between the $\mathrm{CO}_{2}$ and $\mathrm{CH}_{4}$ molar fractions in the HQ clathrate $\left(x^{\mathrm{CO}_{2}}\right.$ and $\left.x^{\mathrm{CH}_{4}}\right)$ and the $\mathrm{CO}_{2}$ and $\mathrm{CH}_{4}$ molar fractions in the gas phase $\left(y^{\mathrm{CO}_{2}}\right.$ and $\left.y^{\mathrm{CH}_{4}}\right)$. The green and blue lines are guides for the eye.

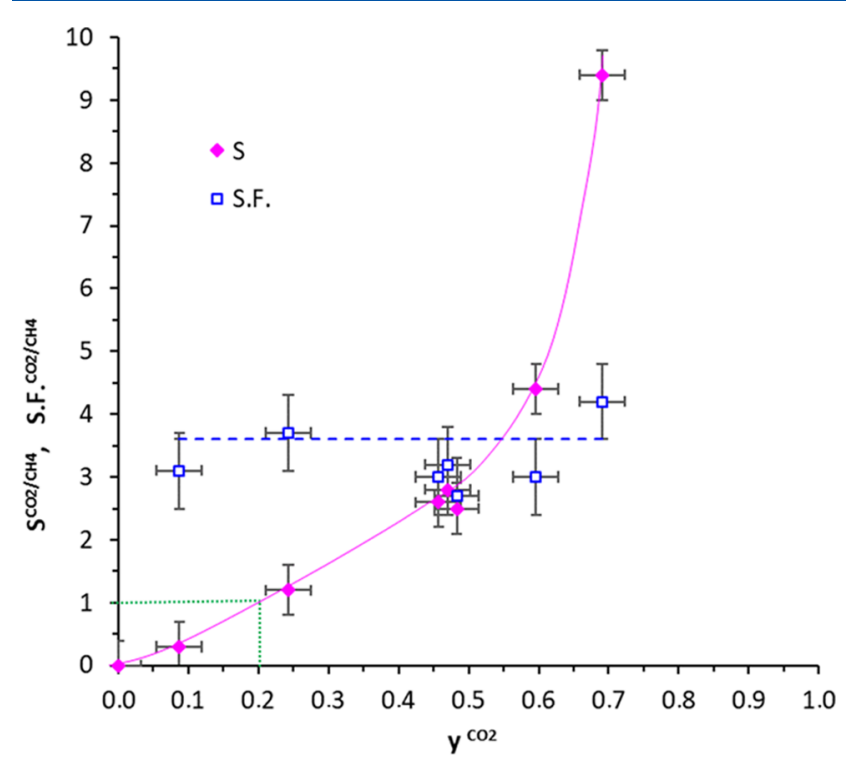

Figure 10. Variation of the ratio of the molar fraction of the $\mathrm{CO}_{2}$ and $\mathrm{CH}_{4}$ present in the crystal $\left(S^{\mathrm{CO}_{2} / \mathrm{CH}_{4}}\right)$ and of the separation factor (SF) as a function of the molar fraction of $\mathrm{CO}_{2}$ in the gas phase. The dashed blue line represents the value $\mathrm{SF}^{\mathrm{CO}_{2} / \mathrm{CH}_{4}}=3.6$. The dotted green lines show the value of the $\mathrm{CO}_{2}$ gas fraction $\left(y^{\mathrm{CO}_{2}} \sim 0.2\right)$, which corresponds to $S^{\mathrm{CO}_{2} / \mathrm{CH}_{4}}=1$. The rose line is guide for the eye.

It is clear that in these conditions of synthesis pressure (3.0 $\mathrm{MPa})$, temperature $(298 \mathrm{~K})$, and gas mixture composition $(0<$ $\left.y^{\mathrm{CO}_{2}}<1\right)$, the $x^{\mathrm{CO}_{2}}$ vs $y^{\mathrm{CO}_{2}}$ curve is always above the diagonal line of this chart (see Figure 9), demonstrating that the molar fraction of $\mathrm{CO}_{2}$ in the solid phase is always higher than in the gas phase at equilibrium. In other words, the gas that could be recovered by dissociation of the clathrate is always richer in $\mathrm{CO}_{2}$ than the gas used to form it. Therefore, the HQ clathrates formed from a $\mathrm{CO}_{2}+\mathrm{CH}_{4}$ gas mixture are selective toward $\mathrm{CO}_{2}$ for the entire gas composition range. This point is illustrated in Figure 10 by $\mathrm{SF}^{\mathrm{CO}_{2} / \mathrm{CH}_{4}}$ values that are greater than 1, i.e., ranging from 2.7 to 4.2 .

Actually, the SF values found in this work are different from those previously published in the literature. Coupan et al. ${ }^{21}$ calculated $\mathrm{SF}^{\mathrm{CO}_{2} / \mathrm{CH}_{4}}$ values lower than 1 across the entire gas composition domain when the clathrate is crystallized from an HQ-saturated solvent solution formed at a very low pressure in conditions of three-phase equilibrium (e.g., $T=298.3 \pm 0.3 \mathrm{~K}$, $P=0.089 \pm 0.013 \mathrm{MPa}$, and $\left.y^{\mathrm{CO}_{2}}=0.512 \pm 0.002\right)$. This comparison might suggest that the clathrate selectivity toward $\mathrm{CO}_{2}$ becomes much higher than 1 if the clathrate formation pressure largely exceeds the three-phase clathrate equilibrium pressure (in this study, the synthesis pressure is around 30 times higher than the equilibrium pressure). In addition, the SF values in this work were found to be about 3-10 times lower than those obtained by Coupan et al. (i.e., $\mathrm{SF}^{\mathrm{CO}_{2} / \mathrm{CH}_{4}}$ from 10.1 to 18.8 at $293 \mathrm{~K})^{17}$ and Lee et al. ${ }^{9}$ who have also worked with $\mathrm{CO}_{2}+\mathrm{CH}_{4}$ gas mixtures. These higher $\mathrm{SF}$ values could be explained by the fact that the mixed gas HQ clathrates found by Coupan et al. and Lee et al. were obtained (i) through a direct gas-solid reaction instead of crystallization from an HQ-saturated solvent, or (ii) through using an intermediate guest-free $\mathrm{HQ}$ clathrate (formed by using $\mathrm{CO}_{2}$ ) identified as being particularly selective toward $\mathrm{CO}_{2}{ }^{10}$ However, even though the $\mathrm{HQ}$ clathrates were selective toward $\mathrm{CO}_{2}$ across the entire gas mixture composition domain, it is very interesting to note in Figure 10 that the clathrate crystals contain more $\mathrm{CO}_{2}$ than $\mathrm{CH}_{4}$ (i.e., $S^{\mathrm{CO}_{2} / \mathrm{CH}_{4}}>1$ ) only when the molar fraction of $\mathrm{CO}_{2}$ in the gas phase $\left(y^{\mathrm{CO}_{2}}\right)$ is higher than around 0.2 . We believe that these results could be very useful for practical applications, such as HQ clathratebased gas separation processes.

\section{CONCLUSIONS}

Single crystals of mixed $\left(\mathrm{CO}_{2}+\mathrm{CH}_{4}\right)-\mathrm{HQ}$ clathrates formed with different $\mathrm{CO}_{2} / \mathrm{CH}_{4}$ gas mixtures were synthesized experimentally and underwent XRD analysis to obtain information on the crystal structures and on the occupancy of the guests enclathrated in the crystal. Molecular dynamics simulations were also performed on the same structures. From the results obtained, it was concluded that mixed $\left(\mathrm{CO}_{2}+\right.$ $\mathrm{CH}_{4}$ ) clathrates have the same rhombohedral crystal structure whatever their composition is (i.e., from pure $\mathrm{CO}_{2}$ to pure $\mathrm{CH}_{4}$ ) and that their homogeneity and concentration depend on cavity size. However, the lattice parameters of the crystal and the size of the cavity vary with the gas mixture composition: when the proportion of $\mathrm{CO}_{2}$ increases in the crystal, the lattice parameters $a$ and $b$ decrease while $c$ increases, in a monotonic way (without extremum). The more $\mathrm{CO}_{2}$ there is in the crystal, the more elongated the cavities toward the $c$-axis. The molecular dynamics simulations very accurately predicted this tendency of the crystal structure to vary according to the gas composition. The lattice parameters obtained in experiments and numerically were in very good agreement, demonstrating that the modeling strategy chosen and the simplified assumptions used are relevant. Interestingly enough, we were able to deduce from the statistical analysis of cavity sizes obtained by simulations, a key aspect of the clathrate structure that is very difficult to process in 
experiments: even if two different guests are present in the structure (i.e., $\mathrm{CO}_{2}$ and $\mathrm{CH}_{4}$ ) in variable proportions, mixed HQ clathrates have just one cavity size that varies as a function of the composition of the gas encapsulated in the crystal. Calculation of clathrate selectivity demonstrated that, in these conditions (synthesis at a pressure of $3.0 \mathrm{MPa}$ and a temperature of $298 \mathrm{~K}$ ), HQ clathrates are always selective toward $\mathrm{CO}_{2}$ whatever the gas composition is:the gas loaded in the clathrates is always richer in $\mathrm{CO}_{2}$ than the gas used to form it. However, it is worth noting that although the clathration was selective toward $\mathrm{CO}_{2}$, we found that the clathrates became richer in $\mathrm{CH}_{4}$ when the $\mathrm{CO}_{2}$ molar fraction in the gas at equilibrium dropped below $\sim 0.2$. We believe that these results concerning clathration selectivity are highly important for practical applications using organic clathrates, particularly $\mathrm{CO}_{2} / \mathrm{CH}_{4}$ gas separation processes based on HQ clathrates. It could be useful to perform additional work at different pressures and temperatures with this particular gas mixture and others.

\section{ASSOCIATED CONTENT}

\section{S Supporting Information}

The Supporting Information is available free of charge on the ACS Publications website at DOI: 10.1021/acs.jpcc.9b04081.

Analytical techniques, methods and materials used in this study, the snapshot of the rhombohedral simulation boxes for the $\beta$-HQ clathrate, the summary of the experimental data obtained, and the statistical analysis of the tilt angle $(\alpha)$ data obtained by simulation (PDF)

\section{Accession Codes}

CCDC 1913196-1913204 contain the additional crystallographic data.

\section{AUTHOR INFORMATION}

\section{Corresponding Author}

*E-mail: jean-philippe.torre@ensiacet.fr. Phone: +33(0)5 34 323710.

\section{ORCID $\odot$}

Jean-Philippe Torré: 0000-0001-5735-8626

Christophe Dicharry: 0000-0002-6318-3989

Manuel M. Piñeiro: 0000-0002-3955-3564

\section{Author Contributions}

The manuscript was written based on the contributions of all the authors. All of the authors have approved the final version of the manuscript.

\section{Notes}

The authors declare no competing financial interest.

\section{ACKNOWLEDGMENTS}

We would like to acknowledge the CNRS (Centre National de la Recherche Scientifique) for supporting this study. We would also like to thank Joseph Diaz and Mathieu Chabod for their assistance with the experimental apparatus. M.M.P. acknowledges the CESGA (www.cesga.es) for providing access to computing facilities and the Ministerio de Economía y Competitividad in Spain for its financial support [Grant ref FIS2015-68910-P cofinanced by European Regional Development Funds (ERDF)].

\section{REFERENCES}

(1) Steed, J. W.; Turner, D. R.; Wallace, K. J. Core Concepts in Supramolecular Chemistry and Nanochemistry; John Wiley \& Sons: Chichester, England, 2007; pp 179-194.

(2) Sloan, E. D.; Koh, C. A. Clathrate Hydrates of Natural Gases, 3rd ed.; CRC Press, Taylor \& Francis Group: Boca Raton, 2008.

(3) Hammerschmidt, E. F. Formation of Gas Hydrates in Natural Gas Transmission Lines. Ind. Eng. Chem. Res. 1934, 26, 851-855.

(4) Atwood, J. L.; Davies, J. E. D.; McNicol, D. D. Structural Aspects of Inclusion Compounds formed by Organic Host lattices; Academic Press Inc.: London, 1984; Vol. 2.

(5) Wöhler, F. Ueber einige Verbindungen aus der Chinonreihe. Justus Liebigs Ann. Chem. 1849, 69, 294-300.

(6) Coupan, R.; Torré, J.-P.; Dicharry, C.; Hemati, M.; Plantier, F. Kinetics of $\mathrm{CO}_{2}$ Capture by Hydroquinone Clathrates. Ind. Eng. Chem. Res. 2018, 57, 8172-8182.

(7) McAdie, H. G. Thermal Decomposition of Molecular Complexes: II. $\beta$-Quinol Clathrates. Can. J. Chem. 1963, 41, 21372143.

(8) Torré, J.P.; Coupan, R.; Chabod, M.; Péré, E.; Labat, S.; Khoukh, A.; Brown, R.; Sotiropoulos, J.-M.; Gornitzka, H. $\mathrm{CO}_{2}-$ Hydroquinone clathrate: Synthesis, Purification, Characterization and Crystal Structure. Cryst. Growth Des. 2016, 16, 5330-5338.

(9) Lee, Y. J.; Han, K. W.; Jang, J. S.; Jeon, T. I.; Park, J.; Kawamura, T.; Yamamoto, Y.; Sugahara, T.; Vogt, T.; Lee, J. W.; et al. Selective $\mathrm{CO}_{2}$ Trapping in Guest free Hydroquinone Clathrate Prepared by Gas Phase Synthesis. ChemPhysChem 2011, 12, 1056-1059.

(10) Coupan, R.; Péré, E.; Dicharry, C.; Torré, J.-P. New Insights on Gas Hydroquinone Clathrates Using in Situ Raman Spectroscopy: Formation/Dissociation Mechanisms, Kinetics, and Capture Selectivity. J. Phys. Chem. A 2017, 121, 5450-5458.

(11) Chleck, D. J.; Ziegler, C. A. The Preparation and Some Properties of Radioactive Quinol-Krypton Clathrate Compounds. Int. J. Appl. Radiat. Isot. 1959, 7, 141-144.

(12) Hayes, D. G.; Bengtsson, Y. C.; Van Alstine, J. M.; Setterwall, F. Urea Complexation for the Rapid, Ecologically Responsible Fractionation of Fatty Acids from Seed Oil. J. Am. Oil Chem. Soc. 1998, 75, 1403-1409.

(13) Han, K. W.; Lee, Y.-J.; Jang, J. S.; Jeon, T.-I.; Park, J.; Kawamura, T.; Yamamoto, Y.; Sugahara, T.; Vogt, T.; Lee, J.-W.; et al. Fast and Reversible Hydrogen Storage in Channel Cages of Hydroquinone Clathrate. Chem. Phys. Lett. 2012, 546, 120-124.

(14) Rozsa, V. F.; Strobel, T. A. Triple Guest Occupancy and Negative Compressibility in Hydrogen-Loaded $\beta$-Hydroquinone Clathrate. J. Phys. Chem. Lett. 2014, 5, 1880-1884.

(15) Lee, J.-W.; Poudel, J.; Cha, M.; Yoon, S. J.; Yoon, J.-H. Highly Selective $\mathrm{CO}_{2}$ Extraction from a Mixture of $\mathrm{CO} 2$ and $\mathrm{H} 2$ Gases Using Hydroquinone Clathrates. Energy Fuels 2016, 30, 7604-7609.

(16) Lee, J.-W.; Dotel, P.; Park, J.; Yoon, J.-H. Separation of $\mathrm{CO}_{2}$ from Flue Gases using Hydroquinone Clathrate Compounds. Korean J. Chem. Eng. 2015, 12, 2507-2511.

(17) Coupan, R.; Dicharry, C.; Torré, J.-P. (2018). Hydroquinone Clathrate Based Gas Separation (HCBGS): Application to the $\mathrm{CO}_{2} /$ $\mathrm{CH}_{4}$ Gas Mixture. Fuel 2018, 226, 137-147.

(18) Powell, H. M. J. The Structure of molecular compounds. Part IV: Clathrate Compounds. J. Chem. Soc. 1948, 61-73.

(19) Conde, M. M.; Torré, J. P.; Miqueu, C. Revisiting the Thermodynamic Modelling of Type I Gas-Hydroquinone Clathrates. Phys. Chem. Chem. Phys. 2016, 18, 10018-10027.

(20) Coupan, R.; Chabod, M.; Dicharry, C.; Diaz, J.; Miqueu, C.; Torré, J.-P. Experimental Determination of Phase Equilibria and Occupancies for $\mathrm{CO}_{2}, \mathrm{CH}_{4}$, and $\mathrm{N}_{2}$ Hydroquinone-Clathrates. $J$. Chem. Eng. Data 2016, 61, 2565-2572.

(21) Coupan, R.; Conde, M. M.; Miqueu, C.; Dicharry, C.; Torré, J.$P$. Phase equilibrium properties of $\mathrm{CO}_{2} / \mathrm{CH}_{4}$ mixed gas hydroquinone clathrates: experimental data and model predictions. J. Chem. Therm. 2018, 116, 230-234. 
(22) Lee, J.-W.; Yoon, J.-H. Preferential Occupation of $\mathrm{CO}_{2}$ Molecules in Hydroquinone Clathrates Formed from $\mathrm{CO}_{2} / \mathrm{N}_{2}$ Gas Mixtures. J. Phys. Chem. C 2011, 115, 22647-22651.

(23) Park, J.-W.; An, S.; Seo, Y.; Kim, B.-S.; Yoon, J.-H. Temperature-Dependent Release of Guest Molecules and Structural Transformation of Hydroquinone Clathrates. J. Phys. Chem. C 2013, 117, 7623-7627.

(24) Coupan, R.; Péré, E.; Dicharry, C.; Plantier, F.; Diaz, J.; Khoukh, A.; Allouche, J.; Labat, S.; Pellerin, V.; Grenet, J.-P.; et al. A Characterization Study of $\mathrm{CO}_{2}, \mathrm{CH}_{4}$, and $\mathrm{CO}_{2} / \mathrm{CH}_{4}$ Hydroquinone Clathrates Formed by Gas-Solid Reaction. J. Phys. Chem. C 2017, 121, 22883-22894.

(25) Lee, J.-W.; Kang, S.-P.; Yoon, J.-H. Competing Occupation of Guest Molecules in Hydroquinone formed from binary $\mathrm{C}_{2} \mathrm{H}_{4}$ and $\mathrm{CH}_{4}$ gas mixtures. J. Phys. Chem. C 2014, 118, 7705-7709.

(26) Lee, J.-W.; Kang, S.-P.; Yoon, J.-H. Highly Selective Enclathration of Ethylene from Gas Mixtures. J. Phys. Chem. C 2014, 118, 6059-6063.

(27) Sum, A. K.; Wu, D. T.; Yasuoka, K. Energy Science of Clathrate Hydrates: Simulation-Based Advances. MRS Bull. 2011, 36, 205-210.

(28) Barnes, B. C.; Sum, A. K. Advances in Molecular Simulations of Clathrate Hydrates. Curr. Opin. Chem. Eng. 2013, 2, 184-190.

(29) Dang, L. X.; Pettitt, B. M. A Theoretical Study of the Inclusion Complexes of $\beta$-Quinol. J. Chem. Phys. 1988, 89, 968-974.

(30) Dang, L. X.; Pettitt, B. M. Thermodynamics of Diatomic Guests in $\beta$-Quinol Clathrates. J. Phys. Chem. 1989, 93, 3794-3799.

(31) Santikary, P.; Yashonath, S.; Rao, C. Molecular Dynamics Simulation of Clathrates: Noble Gases in the Cages of $\beta$-Hydroquinone. Chem. Phys. Lett. 1992, 192, 390-394.

(32) Daschbach, J. L.; Chang, T.-M.; Corrales, L. R.; Dang, L. X.; McGrail, P. Molecular Mechanisms of Hydrogen-Loaded $\beta$-Hydroquinone Clathrate. J. Phys. Chem. B 2006, 110, 17291-17295.

(33) Pérez-Rodríguez, M.; Otero-Fernández, J.; Comesaña, A.; Fernández-Fernández, Á. M.; Piñeiro, M. M. Simulation of Capture and Release Processes of Hydrogen by $\beta$-Hydroquinone Clathrate. ACS Omega 2018, 3, 18771-18782.

(34) Nemkevich, A.; Spackman, M. A.; Corry, B. Mechanism of Concerted Hydrogen Bond Reorientation in Clathrates of Dianin's Compound and Hydroquinone. J. Am. Chem. Soc. 2011, 133, 1888018888 .

(35) Zubkus, V. E.; Shamovsky, I. L.; Tornau, E. E. ComputerSimulation Studies of $\beta$-Quinol Clathrate with Various Gases. Molecular Interactions and Crystal Structure. J. Chem. Phys. 1992, 97, 8617-8627.

(36) Zubkus, V. E.; Shamovsky, I. L. Molecular Interactions, Structure and Stability of $\beta$-Quinol Clathrate. Chem. Phys. Lett. 1992, 195, 135-143.

(37) Comesaña, A.; Pérez-Rodríguez, M.; Fernández, A. M.; Piñeiro, M. M. A Description of Hydroquinone Clathrates Using Molecular Dynamics: Molecular Model and Crystalline Structure for $\mathrm{CH}_{4}$ and $\mathrm{CO}_{2}$ Guests. J. Chem. Phys. 2018, 148, No. 244502.

(38) Li, X.; Chen, Q. Y.; Wang, J. Solubility of Hydroquinone in Different Solvents from $276.65 \mathrm{~K}$ to $345.10 \mathrm{~K}$. J. Chem. Eng. Data 2006, 51, 127-129.

(39) Mercury 3.10.3 (Build 224359), Copyright CCDC 2001-2018. http://www.ccdc.cam.ac.uk/mercury/.

(40) Bekker, H.; Berendsen, H.; Dijkstra, E.; Achterop, S.; Vondrumen, R.; Vanderspoel, D.; Sijbers, A.; Keegstra, H.; Renardus, M. GROMACS: A Parallel Computer for Molecular Dynamics Simulations. In Physics Computing 92; DeGroot, R., Nadrchal, J., Eds.; World Scientific Publishing, 1993; pp 252-256.

(41) Berendsen, H. J. C.; van der Spoel, D.; van Drunen, R. ROMACS: A Message-Passing Parallel Molecular Dynamics Implementation. Comput. Phys. Commun. 1995, 91, 43-56.

(42) Jorgensen, W. L.; Maxwell, D. S.; Tirado-Rives, J. Development and Testing of the OPLS All-Atom Force Field on Conformational Energetics and Properties of Organic Liquids. J. Am. Chem. Soc. 1996, $118,11225-11236$.
(43) Becke, A. D. Density-Functional Thermochemistry. III. The Role of Exact Exchange. J. Chem. Phys. 1993, 98, 5648-5652.

(44) Lee, C.; Yang, W.; Parr, R. G. Development of the ColleSalvetti Correlation-Energy Formula into a Functional of the Electron Density. Phys. Rev. B 1988, 37, 785-789.

(45) Frisch, M. J.; Trucks, G. W.; Schlegel, H. B.; Scuseria, G. E.; Robb, M. A.; Cheeseman, J. R.; Scalmani, G.; Barone, V.; Mennucci, B.; Petersson, G. A.;et al. Gaussian 09, revision D.01; Gaussian, Inc.: Wallingford, CT, 2009.

(46) Breneman, C. M.; Wiberg, K. B. Determining Atom-Centered Monopoles from Molecular Electrostatic Potentials. The Need for High Sampling Density in Formamide Conformational Analysis. J. Comput. Chem. 1990, 11, 361-373.

(47) Bussi, G.; Donadio, D.; Parrinello, M. Canonical Sampling Through Velocity Rescaling. J. Chem. Phys. 2007, 126, No. 014101.

(48) Darden, T.; York, D.; Pedersen, L. Particle Mesh Ewald: An N. $\log (\mathrm{N})$ Method for Ewald Sums in Large Systems. J. Chem. Phys. 1993, 98, 10089-10092.

(49) Essmann, U.; Perera, L.; Berkowitz, M. L.; Darden, T.; Lee, H.; Pedersen, L. G. A Smooth Particle Mesh Ewald Method. J. Chem. Phys. 1995, 103, 8577-8593.

(50) Good, R. J.; Hope, C. J. Test of Combining Rules for Intermolecular Distances. Potential Function Constants from Second Virial Coefficients. J. Chem. Phys. 1971, 55, 111-116.

(51) Turner, M. J.; McKinnon, J. J.; Jayatilaka, D.; Spackman, M. A. Visualisation and Characterisation of Voids in Crystalline Materials. CrystEngComm 2011, 13, 1804-1813.

(52) Johnstone, R. D. L.; Lennie, A. R.; Parker, S. F.; Parsons, S.; Pidcock, E.; Richardson, P. R.; Warren, J. E.; Wood, P. A. HighPressure Polymorphism in Salicylamide. CrystEngComm 2010, 12, $1065-1078$.

(53) Moggach, S. A.; Görbitz, C. H.; Warren, J. E. The Effect of Pressure on the Porous Peptide L-alanyl-L-valine. CrystEngComm 2010, 12, 2322-2324.

(54) Fabbiani, F. P. A.; Levendis, D. C.; Buth, G.; Kuhs, W. F.; Shankland, N.; Sowa, H. Searching for Novel Crystal Forms by in situ High-Pressure Crystallisation: the Example of Gabapentin Heptahydrate. CrystEngComm 2010, 12, 2354-2360.

(55) Mohamed, S.; Karothu, D. P.; Naumov, P. Using Crystal Structure Prediction to Rationalize the Hydration Propensities of Substituted Adamantane Hydrochloride Salts. Acta Crystallogr., Sect. B: Struct. Sci., Cryst. Eng. Mater. 2016, 72, 551-561.

(56) Linga, P.; Kumar, R.; Englezos, P. The Clathrate Hydrate Process for Post and Pre-Combustion Capture of Carbon Dioxide. J. Hazard. Mater. 2007, 149, 625-629. 


\title{
Insights into the Crystal Structure and Clathration
}

\author{
Selectivity of Organic Clathrates formed with \\ Hydroquinone and $\left(\mathrm{CO}_{2}+\mathrm{CH}_{4}\right)$ Gas Mixtures
}

Jean-Philippe TORRÉ ${ }^{1,}{ }^{*}$, Heinz GORNITZKA ${ }^{2}$, Romuald COUPAN ${ }^{3}$, Christophe DICHARRY ${ }^{4}$ Martín PÉREZ-RODRÍGUEZ ${ }^{5}$, Antonio COMESAÑA ${ }^{5}$, Manuel M. PIÑEIRO ${ }^{5}$

1. Laboratoire de Génie Chimique, Université de Toulouse, CNRS, INPT, UPS, Toulouse, France.

2. Laboratoire de Chimie de Coordination LCC-CNRS, Université de Toulouse, CNRS, UPS, Toulouse, France.

${ }^{3}$. Total Research \& Technology Feluy, Zone Industrielle Feluy C, B-7181 Seneffe, Belgium.

4. CNRS/TOTAL/UNIV PAU \& PAYS ADOUR/E2S UPPA, Laboratoire des Fluides Complexes et leurs Réservoirs-IPRA, UMR5150 - avenue de l'Université, 64000 Pau, France.

5. Departamento de Física Aplicada, Facultade de Ciencias, Universidade de Vigo, 36310, Spain. 
Table S1. Analytical techniques and methods used in this study.

\begin{tabular}{|c|c|}
\hline Method & Details \\
\hline GC & $\begin{array}{l}\text { The gas composition at the end of the synthesis is obtained by gas chromatography (GC). } \\
\text { The analysis is performed using a gas chromatograph (GC Agilent, model 7820A) equipped } \\
\text { with a high-pressure sampling system, a } 30 \text {-m capillary column (model HP-PLOT-Q) with } \\
\text { an inner diameter of } 0.32 \mathrm{~mm} \text { (comprising a stationary phase of polystyrene/di-vinylbenzene } \\
\text { coating, } 20 \mu \mathrm{m} \text { thick), and a thermal conductivity detector. Hydrogen, supplied by a } \\
\text { hydrogen generator (model } \mathrm{NMH} \text { ), is used as a carrier gas. The GC is calibrated with } \\
\text { different commercial } \mathrm{CO}_{2} / \mathrm{CH}_{4} \text { gas mixtures. The method allows quantitative measurements } \\
\text { with a relative uncertainty of } 0.3 \% \text {, and retention times for } \mathrm{CH}_{4} \text { and } \mathrm{CO}_{2} \text { of } 0.64 \pm 0.05 \text { and } \\
0.80 \pm 0.05 \text { minutes respectively. }\end{array}$ \\
\hline XRD & $\begin{array}{l}\text { The X-Ray Diffraction (XRD) analysis were performed using oil-coated shock-cooled } \\
\text { crystals on a Bruker-AXS APEX II diffractometer with MoKa radiation ( } \lambda=0.71073 \AA \text { ). } \\
\text { The crystal structures were solved by direct methods [Sheldrick, G. M. Acta Cryst. 2008, } \\
\text { A64, 112-122] and all non-hydrogen atoms were refined anisotropically using the least- } \\
\text { squares method on } \mathrm{F}^{2} \text { [Sheldrick, G. M. Acta Cryst. 2015, C71, 3-8]. }\end{array}$ \\
\hline
\end{tabular}

Table S2. Information concerning the materials used for this study. The products were used without further purification.

\begin{tabular}{llll}
\hline Product & Abbreviation & Purity (mole \%) & Supplier \\
\hline Hydroquinone & $\mathrm{HQ}$ & $99.5 \%$ & Acros Organics \\
Ethanol absolute & $\mathrm{EtOH}$ & $>99 \%$ & Sigma Aldrich \\
Carbon dioxide & $\mathrm{CO}_{2}$ & $>99.995 \%$ & Linde gas \\
Methane & $\mathrm{CH}_{4}$ & $>99.995 \%$ & Linde gas \\
Gas mixtures & $\mathrm{CO}_{2} / \mathrm{CH}_{4}$ & $>99.995 \%$ & Linde gas \\
\hline
\end{tabular}


Table S3. Summary of the experimental data obtained in this study. Variables: $\mathrm{CO}_{2}$ molar fraction in the gas used for the synthesis $\left(y^{\mathrm{CO} 2}\right.$ init), $\mathrm{CO}_{2}$ molar fraction in the gas phase in equilibrium with the solid phase measured at the end of the experiment $\left(y^{\mathrm{CO}}\right), A$ and $\mathrm{B}$ parameters of the clathrate formula $\left(\mathrm{ACO}_{2}\right.$ $\left.-\mathrm{BCH}_{4}-3 \mathrm{HQ}\right)$, crystal lattice parameters $(a, b, c)$, tilt angle of the HQ molecule in the crystal $(\alpha)$, volume of the unit cell $\left(V_{u c}\right)$, total occupancy of the guests in the clathrate $(\chi), \mathrm{CO}_{2}$ molar fraction in the crystal $\left(x^{\mathrm{CO} 2}\right)$, ratio of the $\mathrm{CO}_{2}$ and $\mathrm{CH}_{4}$ molar fractions in the crystal $\left(S^{\mathrm{CO} 2 / C H 4}\right)$, and separation factor $\left(S . F .^{\mathrm{CO} 2: \mathrm{CH} 4}\right)$. The uncertainty $\pm \Delta$ is within the $95 \%$ confidence interval of the mean, under the assumption of normality, estimated from 3 repeat experiments (CDCC 1913199-1913201).

\begin{tabular}{|c|c|c|c|c|c|c|c|c|c|c|c|c|}
\hline Variable & $y^{\mathrm{CO}{ }_{\text {init }}}$ & $y^{\mathrm{CO} 2}$ & $A$ & B & $a, b$ & $c$ & $\alpha$ & $V_{u c}$ & $\chi$ & $x^{C O 2}$ & $\mathrm{~S}^{\mathrm{CO} 2 / \mathrm{CH} 4}$ & S.F. ${ }^{\mathrm{CO} 2 / \mathrm{CH} 4}$ \\
\hline unit & - & - & - & - & $\AA$ & A & deg & $A^{3}$ & - & - & - & - \\
\hline$\pm \Delta$ & 0.008 & 0.032 & 0.06 & 0.06 & 0.042 & 0.014 & 0.4 & 4 & 0.12 & 0.03 & 0.4 & 0.6 \\
\hline $\begin{array}{c}\text { CDCC- } \\
1913196\end{array}$ & 0.000 & 0.000 & 0.00 & 0.81 & 16.562 & 5.405 & 40.2 & 1284 & 0.81 & 0.00 & 0.0 & - \\
\hline $\begin{array}{c}\text { CDCC- } \\
1913197\end{array}$ & 0.106 & 0.087 & 0.19 & 0.65 & 16.529 & 5.430 & 40.7 & 1285 & 0.84 & 0.23 & 0.3 & 3.1 \\
\hline $\begin{array}{c}\text { CDCC- } \\
1913198\end{array}$ & 0.255 & 0.243 & 0.39 & 0.33 & 16.416 & 5.496 & 41.7 & 1283 & 0.72 & 0.54 & 1.2 & 3.7 \\
\hline $\begin{array}{c}\text { CDCC- } \\
1913199\end{array}$ & 0.502 & 0.483 & 0.58 & 0.23 & 16.321 & 5.580 & 42.9 & 1287 & 0.81 & 0.72 & 2.5 & 2.7 \\
\hline $\begin{array}{c}\text { CDCC- } \\
1913200\end{array}$ & 0.497 & 0.457 & 0.59 & 0.23 & 16.325 & 5.573 & 42.8 & 1286 & 0.82 & 0.72 & 2.6 & 3.0 \\
\hline $\begin{array}{c}\text { CDCC- } \\
1913201\end{array}$ & 0.503 & 0.470 & 0.54 & 0.19 & 16.352 & 5.569 & 42.6 & 1289 & 0.73 & 0.74 & 2.8 & 3.2 \\
\hline $\begin{array}{c}\text { CDCC- } \\
1913202\end{array}$ & 0.640 & 0.596 & 0.71 & 0.16 & 16.265 & 5.623 & 43.4 & 1288 & 0.87 & 0.82 & 4.4 & 3.0 \\
\hline $\begin{array}{c}\text { CDCC- } \\
1913203\end{array}$ & 0.742 & 0.691 & 0.75 & 0.08 & 16.235 & 5.644 & 43.8 & 1288 & 0.83 & 0.90 & 9.4 & 4.2 \\
\hline $\begin{array}{c}\text { CDCC- } \\
1913204\end{array}$ & 1.000 & 1.000 & 0.83 & 0.00 & 16.189 & 5.688 & 44.3 & 1291 & 0.83 & 1.00 & - & - \\
\hline
\end{tabular}


Table S4. Statistical analysis with the data of Figure 6 (distribution of the tilt angle $(\alpha)$ of the HQ molecule in the clathrate structure for three values of $\mathrm{CO}_{2}$ molar fractions in the solid). Number of observations: 576. The Kolmogorov-Smirnov test was used to evaluate whether scores were likely to follow normal distribution in the populations.

\begin{tabular}{cccccc}
\cline { 2 - 5 } & Min & Max & Average & Std deviation & $\begin{array}{c}p \text {-value } \\
\text { (Kolmogorov- } \\
\text { Smirnov test) }\end{array}$ \\
\hline $\mathrm{x}=0$ & 35.495 & 39.411 & 37.427 & 0.686 & 0.875 \\
$\mathrm{x}=0.5$ & 35.767 & 42.187 & 39.466 & 1.099 & 0.608 \\
$\mathrm{x}=1$ & 40.891 & 45.206 & 43.067 & 0.698 & 0.985 \\
\hline
\end{tabular}

(1) if the $p$-value is $>0.05$, the assumption of normality cannot be rejected (i.e. the data follow normal distribution). 